\title{
Rise of serum troponin levels following uncomplicated elective percutaneous coronary interventions in patients without clinical and procedural signs suggestive of myocardial necrosis
}

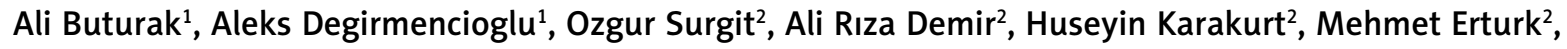 \\ Selcuk Yazıci ${ }^{3}$, Mustafa Serteser ${ }^{4}$, Tugrul Norgaz ${ }^{1}$, Sevket Gorgulu ${ }^{1}$ \\ ${ }^{1}$ Department of Cardiology, School of Medicine, Acıbadem University, Istanbul, Turkey \\ ${ }^{2}$ Cardiology Department, Mehmet Akif Ersoy Education and Research Hospital, Istanbul, Turkey \\ ${ }^{3}$ Cardiology Department, Siyami Ersek Education and Research Hospital, Istanbul, Turkey \\ ${ }^{4}$ Medical Biochemistry Department, Faculty of Medicine, Acibadem University, Istanbul, Turkey
}

Adv Interv Cardiol 2016; 12, 1 (43): 41-48

DOI: $10.5114 /$ pwki.2016.56948

\begin{abstract}
A bstract
Introduction: The new definition of periprocedural myocardial infarction (type 4a MI) excludes patients without angina and electrocardiographic or echocardiographic changes suggestive of myocardial ischemia even though significant serum troponin elevations occur following percutaneous coronary intervention (PCI).

Aim: To evaluate the incidence and predictors of serum troponin rise following elective $\mathrm{PCl}$ in patients without clinical and procedural signs suggestive of myocardial necrosis by using a high-sensitivite troponin assay (hsTnT).

Material and methods: Three hundred and four patients (mean age: $60.8 \pm 8.8$ years, 204 male) undergoing elective $\mathrm{PCl}$ were enrolled. Patients with periprocedural angina, electrocardiographic or echocardiographic signs indicating myocardial ischemia or a visible procedural complication such as dissection or side branch occlusion were excluded. Mild-moderate periprocedural myocardial injury (PMI) and severe PMI were defined as post-PCI (12 h later) elevation of serum hsTnT concentrations to the range of 14-70 ng/l and > $70 \mathrm{ng} / \mathrm{l}$, respectively.

Results: The median pre-procedural hsTnT level was $9.7 \mathrm{ng} / \mathrm{l}$ (interquartile range: 7.1-12.2 ng/l). Serum hsTnT concentration elevated $(p<0.001)$ to $19.4 \mathrm{ng} / \mathrm{l}(\mathrm{IQR}: 12.0-38.8 \mathrm{ng} / \mathrm{l}) 12 \mathrm{~h}$ after $\mathrm{PCl}$. Mild-moderate PMI and severe PMI were detected in $49.3 \%$ and $12.2 \%$ of patients, respectively. Post-procedural hsTnT levels were significantly higher in multivessel PCl, overlapping stenting, predilatation and postdilatation subgroups. In addition, post-procedural hsTnT levels were correlated $(r=0.340 ; p<0.001)$ with the stent lengths.

Conclusions: High-sensitivite troponin measurements indicate a high incidence of PMI even though no clinical or procedural signs suggestive of myocardial ischemia exist. Multivessel PCI, overlapping stenting, predilatation, postdilatation and longer stent length are associated with PMI following elective PCI.
\end{abstract}

Key words: injury, coronary, procedural.

\section{Introduction}

The treatment of atherosclerotic coronary artery disease has been improved by the utility of percutaneous coronary intervention $(\mathrm{PCl})$ performed by experienced operators. Even though $\mathrm{PCl}$ is safe in the majority of cases, periprocedural myocardial injury (PMI) may occur following the procedures. Side branch occlusion, coronary dissection and distal embolization of the plaque debris may lead to PMI with an incidence of $5-30 \%$ reported by several studies [1, 2]. However, PMI may also occur in cases of successful and uneventful PCl procedures without any visible complications [3].

Cardiac troponins are established biomarkers in detecting myocardial injury due to their high specificity and sensitivity. Elevation of cardiac troponins above the $99^{\text {th }}$

Corresponding author:

Ali Buturak MD, Department of Cardiology, School of Medicine, Acıbadem University, Acibadem Hastanesi, Tekin Sokak, No: 8, Acibadem, 34720 Istanbul, Turkey, phone: +90 2165444063, e-mail: alibuturak@yahoo.com

Received: 24.05.2015, accepted: 30.06.2015. 
percentile of the upper reference limit (URL) in the presence of a normal baseline troponin value has been defined as PMI [4]. Percutaneous coronary intervention-related myocardial infarction (type $4 \mathrm{a} \mathrm{MI}$ ) has also been recently defined as elevation of serum cardiac biomarkers more than five times the $99^{\text {th }}$ percentile of URL with periprocedural anginal symptoms suggestive of myocardial ischemia or new ischemic electrocardiographic changes or new segmental wall motion abnormality detected by echocardiography [5]. Although lower biomarker elevations ( $<$ three times the $99^{\text {th }}$ percentile of URL) have been thought to be less associated with adverse outcomes in early and long-term follow-up, any troponin elevation is accepted as an important predictor of adverse in-hospital cardiac events (death, acute myocardial infarction, target lesion revascularization) and long-term adverse outcomes as repeat $\mathrm{PCl}$, readmission for angina, need for bypass surgery, acute coronary syndrome (ACS) and death up to 1 year following interventions [6-8].

A high sensitive assay for cardiac troponin T (hsTnT) has been developed, capable of measuring concentrations that are lower than those with conventional troponin assays. Recent studies have demonstrated that hsTnT can improve early diagnosis of acute myocardial infarction (MI) and allow risk stratification of patients with congestive heart failure, ACS, and stable coronary artery disease [9-11]. However, there is no satisfactory data regarding the use of hsTnT in detecting PMI following elective PCI procedures without any visible complications such as side branch plaque shifting, coronary dissection or no-reflow. In addition, the new definition of type $4 \mathrm{a} \mathrm{MI}$ excludes patients without anginal symptoms, electrocardiographic changes or new wall motion abnormalities detected by echocardiography even though more than five-fold elevations occur according to baseline troponin values. A pure significant elevation of cardiac biomarkers following PCl without anginal symptoms or signs of myocardial injury detected by non-invasive modalities constitutes a gray zone which should be further evaluated.

\section{Aim}

Therefore, we aimed to evaluate the incidence of procedure-related myocardial injury by measuring hsTnT concentrations in patients with stable angina pectoris with successful and uneventful $\mathrm{PCl}$ procedures without objective signs of ischemia or myocardial necrosis detected by non-invasive modalities. The present study also investigated the clinical and procedural predictors of PMI following elective $\mathrm{PCl}$.

\section{Material and methods \\ Patient population}

Three hundred and twenty consecutive patients undergoing elective $\mathrm{PCl}$ were prospectively enrolled from October 2013 to June 2014 at two different centers.
Patients who presented with stable angina pectoris on optimal medical therapy and ischemia documented by treadmill exercise stress test, stress echocardiography or myocardial perfusion scintigraphy underwent the procedures. Percutaneous coronary intervention was performed in patients who had at least one significant coronary artery stenosis amenable to revascularization. Patients presenting with acute MI, unstable angina pectoris, decompensated heart failure with either reduced or preserved ejection fraction (EF \%), compensated heart failure with reduced EF (<35\%), compensated heart failure with preserved EF ( $>50 \%)$, chronic renal failure, active infection, and history of chronic inflammatory disease were not enrolled in the study. Twelve patients with pre-procedural serum hsTnT $\geq 14 \mathrm{ng} / \mathrm{l}$, 2 patients with coronary dissection and 2 patients with side branch occlusion during main vessel stenting were excluded. Electrocardiography and echocardiography were performed in all participants before and after the procedures to detect any dynamic change. The final study group consisted of 304 patients with successful and uncomplicated $\mathrm{PCl}$ procedures. Written informed consent was obtained from all patients before commencement and the study protocol and the contents of the written consent form were approved by the Institutional Ethics Committee.

\section{Coronary lesion classification and procedural definitions}

Angiograms were acquired with a cine-angiographic equipment (Siemens Artis Zee system, Forchheim, Germany) in different orthogonal views. The percent diameter stenosis (\%) of the coronary lesions was obtained by quantitative coronary angiography (QCA) software with digital calibration. Significant stenosis was defined as $\geq 70 \%$ diameter narrowing in a coronary artery or coronary artery stenosis with fractional flow reserve $(F F R) \leq 0.80$.

Lesion classification was defined according to the Society for Cardiac Angiography and Interventions (SCAI) lesion classification system [12], which uses type C lesion characteristics [13] as the key determinant of lesion complexity. Accordingly, we defined four different lesion types (SCAl type 1-4) based on the SCAI classification system.

Multivessel $\mathrm{PCl}$ was defined as stenting in two or more major coronary arteries or bypass grafts which supply different myocardial territories.

Overlapping stenting was defined as the presence of $\geq 2$ stents within a single treated lesion and an overlapping stent zone of at least $1 \mathrm{~mm}$.

\section{Definitions of PMI severity}

Severe myocardial injury (severe PMI) was defined as an elevation in serum hsTnT to more than $70 \mathrm{ng} / \mathrm{l}$ (more than 5 times the $99^{\text {th }}$ percentile URL of the hsTnT assay).

Mild-moderate myocardial injury (mild-moderate PMI) was defined as elevation of hsTnT concentrations 
to the range of $14-70 \mathrm{ng} / \mathrm{l}$ following $\mathrm{PCl}(\geq 14 \mathrm{ng} / \mathrm{l}-$ $<70 \mathrm{ng} / \mathrm{l})$.

\section{Percutaneous coronary intervention procedure}

Standard techniques were performed via a femoral or radial approach with 6 or $7 \mathrm{Fr}$ sheaths. All objectives were preloaded with $300 \mathrm{mg}$ aspirin and $600 \mathrm{mg}$ clopidogrel before the procedures. Intravenous heparin (70 to $100 \mathrm{UI} / \mathrm{kg}$ ) was administered before $\mathrm{PCl}$ with subsequent bolus doses to maintain an activating clotting time between 250 and 300 s. Predilatation was performed according to the lesion severity and characteristics. Direct stenting was done in suitable cases. Postdilatation with a non-compliant (NC) balloon was performed in cases of insufficient stent expansion or in PCls which required final kissing balloon dilatation. Drug-eluting and bare metal stents were used for stenting.

\section{Serum hsTnT measurements}

Peripheral venous blood samples were collected just before $\mathrm{PCl}$ and $12 \mathrm{~h}$ after the procedures. The plasma supernatant was separated and stored frozen at $-80^{\circ} \mathrm{C}$ until analysis. Serum cardiac troponin $\mathrm{T}$ was measured by Elecsys Troponin T-High Sensitive Immunoassay (Roche Diagnostics, Rotkreuz, Switzerland) with an analytical measurement range of 3-10,000 $\mathrm{ng} / \mathrm{l}$ or $\mathrm{pg} / \mathrm{ml}$. The lower limit of detection was $5 \mathrm{ng} / \mathrm{l}$. The values $<5 \mathrm{ng} / \mathrm{l}$ were excluded from statistical analyses. The upper reference limit (99 ${ }^{\text {th }}$ percentile) for troponin T was $14 \mathrm{ng} / \mathrm{l}(\mathrm{pg} / \mathrm{ml})$.

\section{Statistical analysis}

All analyses were performed using SigmaPlot 11.0 statistical software (Systat Software Inc., San Jose, California). Discrete variables were reported as percentages and were compared using the $\chi^{2}$ test. Continuous variables with normal distribution (age, body mass index, left ventricular ejection fraction, stent length, stent diameter) were reported as mean ( \pm standard deviations) values and compared using the $t$-test. Non-normally distributed variables were presented as median with interquartile (25-75\%) range (IQR), and for comparison between groups either the Kruskal-Wallis (between 3 groups) or the Mann-Whitney $U$ test (between two groups) was used. For categorical data, the $\chi^{2}$ or Fisher's exact test was used where appropriate. Correlations between serum hsTnT concentrations and other parameters were analyzed using Pearson product-moment correlation analysis. Univariate and multivariate logistic regression analyses were performed to identify the predictors of the elevation in serum hsTnT concentrations. All variables with a $p$ value $<0.1$ in the univariate analysis were included in the multivariate model. Serum hsTnT concentrations were adjusted for clinical and procedural characteristics of patients using weighted least square regression analysis. A probability value of $<0.05$, with $\geq 0.80$ statistical power, was considered significant.

\section{Results}

\section{Patient characteristics}

Table I summarizes baseline demographic and clinical characteristics of the patients. The average age of the study population was $60.9 \pm 8.8$ years (median: 61.0, interquartile range: 55.0-67.0). All the patients were stable and none of them complained of ischemic type chest pain during or after the procedures. Post- $\mathrm{PCl}$ electrocardiography and echocardiography did not reveal any dynamic change.

\section{Procedural data}

Percutaneous coronary intervention procedures were completed successfully without complications such as coronary dissection or perforation, no-reflow, side branch occlusion and visible distal embolization of plaque debris deteriorating the antegrade flow. Table II demonstrates the procedural data of the study population.

\section{Serum hsTnT concentrations}

In 63 (20.7\%) patients, serum pre-procedural serum hsTnT concentrations were at or below the limit of detection of the assay $(5 \mathrm{ng} / \mathrm{l})$. The average pre-procedural hsTnT level was $9.6 \pm 2.7 \mathrm{ng} / \mathrm{l}$ (median: $9.7 \mathrm{ng} / \mathrm{l}$; interquartile range: $7.1-12.2 \mathrm{ng} / \mathrm{l})$. In 285 (93.8\%) patients, serum post-procedural hsTnT concentrations were found increased from baseline hsTnT values, whereas the

Table I. Demographic and clinical characteristics of patients

\begin{tabular}{ll}
\hline Age $[$ years] & $60.8 \pm 8.8^{*}$ \\
\hline Body mass index $\left[\mathrm{kg} / \mathrm{m}^{2}\right]$ & $27.6 \pm 4.2^{*}$ \\
\hline Male, $n(\%)$ & $204(67.1)$ \\
\hline Female, $n(\%)$ & $100(32.9)$ \\
\hline Smoking, $n(\%)$ & $81(26.6)$ \\
\hline Diabetes mellitus, $n(\%)$ & $107(35.2)$ \\
\hline Hypertension, $n(\%)$ & $202(66.4)$ \\
\hline Previous MI, $n(\%)$ & $62(20.4)$ \\
\hline Previous PCI, $n(\%)$ & $71(23.3)$ \\
\hline Previous CABG, $n$ (\%) & $29(9.5)$ \\
\hline LVEF (\%) & $67.3 \pm 3.5^{*}$ \\
\hline Statin user, $n$ (\%) & $134(44.1)$ \\
\hline$\beta$-Adrenoceptor antagonist user, $n(\%)$ & $194(63.8)$ \\
\hline ACEl/ARB, $n$ (\%) & $174(57.3)$
\end{tabular}

Data are median (interquartile range) or number of patients (percentage). *Indicates values reported as mean \pm standard deviation. $n$ - number, $\mathrm{Ml}-$ myocardial infarction, $\mathrm{PCl}$ - percutaneous coronary intervention, CABG - coronary artery bypass grafting, LVEF (\%) - left ventricular ejection fraction (\%), ACEII $A R B$ - angiotensin-converting enzyme inhibitors-angiotensin receptor blockers. 
Table II. Procedural characteristics of patients

\begin{tabular}{lc}
\hline Coronary lesion classification, $n(\%):$ & \\
\hline Type 1 & $140(46.1)$ \\
\hline Type 2 & $152(50.0)$ \\
\hline Type 3 & $8(2.6)$ \\
\hline Type 4 & $4(1.3)$ \\
\hline Transfemoral access, $n$ (\%) & $195(64.1)$ \\
\hline Transradial access, $n(\%)$ & $109(35.9)$ \\
\hline Ostial lesion PCI, $n(\%)$ & $18(5.9)$ \\
\hline Bifurcation lesion PCI, $n(\%)$ & $30(9.9)$ \\
\hline Saphenous vein graft PCI, $n(\%)$ & $8(2.6)$ \\
\hline In-stent restenosis PCI, $n(\%)$ & $19(6.3)$ \\
\hline CTO lesion PCI, $n(\%)$ & $12(3.9)$ \\
\hline Single vessel PCI, $n(\%)$ & $267(87.8)$ \\
\hline Multivessel PCI, $n(\%)$ & $37(12.2)$ \\
\hline Predilatation, $n(\%)$ & $184(60.5)$ \\
\hline Postdilatation, $n(\%)$ & $97(31.9)$ \\
\hline Overlapping stenting, $n(\%)$ & $42(13.8)$ \\
\hline Stent length, mean $\pm \mathrm{SD}[\mathrm{mm}]$ & $24.0 \pm 11.7^{\#}$ \\
\hline Stent diameter, mean $\pm \mathrm{SD}[\mathrm{mm}]$ & $3.0 \pm 0.4^{\#}$ \\
\hline DES, $n$ (\%) & $178(58.6)$ \\
\hline BMS, $n(\%)$ & $126(41.4)$ \\
\hline
\end{tabular}

$P C I$ - Percutaneous coronary intervention, CTO - chronic total occlusion $D E S$ - drug-eluting stent, BMS - bare metal stent. Data are number of patients (percentage). "Indicates values reported as mean \pm standard deviation.

post-procedural hsTnT concentrations remained at or below $5 \mathrm{ng} / \mathrm{l}$ in 19 patients. The average post-procedural hsTnT level was $34.4 \pm 43.5 \mathrm{ng} / \mathrm{l}$ (median: $19.4 \mathrm{ng} / \mathrm{l}$; interquartile range: $12.0-38.8 \mathrm{ng} / \mathrm{l})$, higher $(p<0.001)$ than the pre-procedural serum hsTnT concentrations. The amount of increase from the baseline hsTnT concentration was $25.8 \pm 2.6 \mathrm{ng} / \mathrm{l}$ (median $9.6 \mathrm{ng} /$; interquartile range: $3.9-27.6 \mathrm{ng} / \mathrm{l})$.

\section{Incidence of mild-moderate PMI and severe PMI}

Post-procedural serum hsTnT concentrations in 187 (61.5\%) patients were above the $99^{\text {th }}$ percentile of URL (14 ng/l). In 37 (12.2\%) patients, the post-procedural serum hsTnT concentrations were higher than $70 \mathrm{ng} / \mathrm{l}$. The incidence of mild-moderate PMI and severe PMI were $49.3 \%$ and $12.2 \%$, respectively (Table III).

Serum hs'TnT concentrations and incidence of mild-moderate PMI and severe PMI according to baseline characteristics

Table III summarizes serum hsTnT concentrations and the incidence of mild-moderate PMI and severe PMI in patient subgroups according to the demographic and clinical characteristics. Serum post-procedural hsTnT concentrations were higher than their pre-procedural hsTnT concentrations in all patient subgroups. In patients with a history of coronary artery bypass grafting (CABG), the average serum post-procedural hsTnT concentration was higher $(p<0.01)$ than the observed values in patients without $C A B G$ history. In addition, the incidence of mild-moderate PMI or severe PMI was similar in all subgroups (Table III).

Serum hsTnT concentrations and incidence of mild-moderate PMI and severe PMI according to procedural characteristics

Serum hsTnT concentrations and the incidence of mild-moderate PMI and severe PMI in patient subgroups according to the procedural characteristics are shown in Table IV. Serum post-procedural hsTnT concentrations were higher $(p<0.001)$ than their pre-procedural concentrations in all patient groups. The average serum post-procedural hsTnT concentrations in patients with multivessel PCI were higher $(p<0.01)$ than the observed post-procedural hsTnT concentrations in the single vessel PCI group. Similarly, patients with overlapping stenting revealed higher serum post-procedural hsTnT concentrations compared with patients without overlapping stenting. In addition, predilatation, post-dilatation, and combination of pre-and post-dilatation subgroups indicated higher post-procedural hsTnT serum levels compared with respective patient subgroups, as shown in Table IV.

The incidence of mild-moderate PMI was similar in all subgroups. The incidence of severe PMI was higher in overlapping stenting, predilation, postdilation, or combination of predilatation and postdilatation subgroups (Table IV).

Correlations of serum hs' $\mathrm{Tn} \mathrm{T}$ concentrations with demographic, clinical and procedural factors

To assess the relative contribution of potential determinants of serum hsTnT concentrations, Pearson's correlation and series of regression analyses were conducted with hsTnT concentrations. There was a weak positive association $(r=0.224 ; p<0.001)$ between preand post-procedural serum hsTnT concentrations. There was a positive correlation between age and pre-procedural hsTnT concentration $(r=0.201 ; p<0.001)$, but not post-procedural serum hsTnT concentration $(r=0.103$; $p=0.073$ ). Multivariate regression analysis revealed that gender, smoking, hypertension, diabetes mellitus, use of statins, and $\beta$-blockers were not determinants for serum pre-procedural or post-procedural hsTnT concentrations (Table V). However, regression analysis showed that age, prior $\mathrm{MI}$, prior $\mathrm{PCl}$, prior $\mathrm{CABG}$ and use of angiotensin-converting enzyme inhibitors/angiotensin re- 
Table III. Serum pre-procedural and post-procedural hsTnT concentrations and incidence of mild-moderate PMI and severe PMI in patient subgroups according to demographic and clinical characteristics

\begin{tabular}{|c|c|c|c|c|}
\hline Parameter & $\begin{array}{c}\text { Pre-PCI hsTnT [ng/l] } \\
\text { Median (25-75\%) }\end{array}$ & $\begin{array}{c}\text { Post-PCI hsTnT [ng/l] } \\
\text { Median (25-75\%) }\end{array}$ & $\begin{array}{c}\text { Mild-moderate PMI } \\
n(\%)\end{array}$ & $\begin{array}{c}\text { Severe PMI } \\
n(\%)\end{array}$ \\
\hline All patients $(n=304)$ : & $9.6(7.1-12.3)$ & $19.4(12.0-38.8)^{*}$ & $150(49.3)$ & $37(12.2)$ \\
\hline Male $(n=204)$ & $9.3(7.0-12.2)$ & $19.5(11.4-36.4)^{*}$ & $97(47.5)$ & $25(12.3)$ \\
\hline Female $(n=100)$ & $9.8(7.5-12.5)$ & $19.0(12.7-40.5)^{\star}$ & $53(53.0)$ & $12(12.0)$ \\
\hline Smokers $(n=81)$ & $9.2(7.2-12.4)$ & $19.6(11.0-38.2)^{\star}$ & $36(44.4)$ & $13(16.4)$ \\
\hline Non-smokers $(n=223)$ & $9.6(7.1-12.0)$ & $19.2(12.2-38.8)^{*}$ & $115(51.6)$ & $24(10.7)$ \\
\hline Diabetic $(n=107)$ & $9.1(6.9-12.4)$ & $20.2(11.9-41.7)^{\star}$ & $56(52.3)$ & $11(10.3)$ \\
\hline Non-diabetic $(n=197)$ & $9.8(7.4-12.0)$ & $17.4(12.2-29.3)^{\star}$ & $94(47.7)$ & $26(13.2)$ \\
\hline Normotensive $(n=102)$ & $8.3(6.9-11.6)$ & $22.0(11.9-41.7)^{\star}$ & $48(47.1)$ & $13(12.7)$ \\
\hline Hypertensive $(n=202)$ & $9.9(7.3-12.3)$ & $18.9(12.0-31.7)^{*}$ & $102(50.5)$ & $24(11.9)$ \\
\hline Previous MI $(n=62)$ & $9.0(6.5-11.6)$ & $22.7(12.9-44.3)^{\star}$ & $32(51.6)$ & $7(11.2)$ \\
\hline No previous MI $(n=242)$ & $9.8(7.3-12.3)$ & $19.3(11.6-38.0)^{\star}$ & $119(49.2)$ & $29(12.0)$ \\
\hline Previous PCI $(n=71)$ & $10.8(7.8-13.0)^{4}$ & $20.9(12.9-41.3)^{*}$ & $38(53.5)$ & $9(12.7)$ \\
\hline No previous $\mathrm{PCI}(n=233)$ & $9.2(6.9-11.8)$ & $19.2(11.4-36.7)^{\star}$ & $112(48.1)$ & $28(12.0)$ \\
\hline Previous CABG $(n=29)$ & $11.0(9.0-12.9)$ & $26.6(19.7-57.9)^{\star \bullet}$ & $22(75.9)$ & $3(10.4)$ \\
\hline No previous CABG $(n=275)$ & $9.2(7.1-12.0)$ & $18.7(11.5-36.6)^{\star}$ & $128(46.5)$ & $34(12.4)$ \\
\hline Statin user $(n=134)$ & $9.9(7.5-12.1)$ & $19.7(11.7-39.5)^{\star}$ & $72(53.7)$ & $15(11.2)$ \\
\hline Non-user $(n=170)$ & $9.3(6.9-12.8)$ & $19.3(12.2-37.0)^{*}$ & $78(45.9)$ & $22(12.9)$ \\
\hline$\beta$-Blocker user $(n=194)$ & $9.8(6.9-12.5)$ & $19.8(12.5-40.4)^{*}$ & $102(52.6)$ & $23(11.9)$ \\
\hline Non-user $(n=110)$ & $9.6(7.7-12.2)$ & $18.9(11.4-33.8)^{*}$ & $48(43.6)$ & $14(12.7)$ \\
\hline ACEI/ARB user $(n=174)$ & $10.5(7.6-12.9)^{9}$ & $19.6(12.8-35.0)^{*}$ & $98(56.3)$ & $20(11.5)$ \\
\hline Non-user $(n=130)$ & $8.3(6.9-11.3)$ & $19.0(10.2-39.3)^{*}$ & $52(40.0)$ & $17(10.0)$ \\
\hline
\end{tabular}

Pre-PCI hsTnT-Pre-procedural serum high-sensitivity troponin T level, post-PCI hsTnT-post-procedural serum high-sensitivity troponin T level, PMI - periprocedural myocardial injury, $\mathrm{MI}$ - myocardial infarction, $P C l$ - percutaneous coronary intervention, $C A B G$ - coronary artery bypass grafting, $A C E l / A R B$ - angiotensin-converting enzyme inhibitors-angiotensin receptor blockers. Data are median (interquartile range) or number of patients (percentage). *Significantly higher than the respective values of pre-PCI hsTnT concentrations. "Significantly higher than the values observed in the respective group.

ceptor blockers (ACEI/ARB) had a significant influence on pre-procedural hsTnT concentrations. Multivariate regression analysis also indicated that predilatation, overlapping stenting and stent length had a significant effect on post-procedural hsTnT concentrations. In addition, stent length apparently had a significant impact on the increase in hsTnT levels.

\section{Discussion}

The main findings of the present study are: 1) serum hsTnT concentrations increased in $93.8 \%$ of the patients after uncomplicated elective PCIs; 2) mild-moderate PMI and severe PMI occurred in $49.3 \%$ and $12.2 \%$ of the patients; 3) overlapping stenting, multivessel $\mathrm{PCl}$, predilation and postdilatation increased the magnitude of the myocardial injury; and 4) longer stent length is associated with PMI.

PMI has prognostic importance in both early and long-term follow-up. Even though no clinical and angiographic signs of revascularization failure exist, PMI may occur silently after uneventful PCls. Not only in-hospi- tal adverse cardiac events such as death and acute $\mathrm{MI}$ may occur, but also long-term poor outcomes such as repeat $\mathrm{PCl}$, readmission for angina, need for CABG, ACS and death up to one year following interventions may complicate $\mathrm{PCl}$ procedures at late term [6]. It has been revealed in a previous study that one quarter of low-risk patients experience a type $4 \mathrm{a} \mathrm{Ml}$ according to revised definition and rises in troponin are significantly associated with periprocedural ischemic symptoms or electrocardiographic changes and abciximab use [14].

Advanced age, reduced left ventricular ejection fraction, multivessel coronary artery disease (CAD), diffuse $C A D$ and preexisting renal impairment are patient-related baseline predisposing factors that may lead to PMI [15]. The present study revealed a positive correlation between age and pre-procedural hsTnT levels. Recently published studies demonstrated that advanced age was an independent predictive factor of elevated hsTnT at admission without a diagnosis of ACS [16, 17]. Elderly patients have more complex structural heart disease and may have comorbidities such as heart failure, renal im- 
Table IV. Serum pre-procedural hsTnT concentrations, post-procedural hsTnT concentrations and incidence of mild-moderate PMI and severe PMI in patient subgroups according to procedural characteristics

\begin{tabular}{|c|c|c|c|c|}
\hline Procedural groups & $\begin{array}{c}\text { Pre-PCI hsTnT [ng/l] } \\
\text { Median (25-75\%) }\end{array}$ & $\begin{array}{c}\text { Post-PCl hsTnT [ng/l] } \\
\text { Median (25-75\%) }\end{array}$ & $\begin{array}{c}\text { Mild-moderate PMI } \\
n(\%)\end{array}$ & $\begin{array}{c}\text { Severe PMI } \\
n(\%)\end{array}$ \\
\hline Femoral $(n=195)$ & $8.9(6.9-11.3)$ & $19.4(12.0-36.8)^{\star}$ & $98(50.3)$ & $22(11.3)$ \\
\hline Radial $(n=109)$ & $9.9(7.4-12.8)$ & $19.4(11.8-39.5)^{*}$ & $67(61.5)$ & $15(15.8)$ \\
\hline Lesion type $1(n=140)$ & $9.4(6.9-11.9)$ & $15.3(10.7-26.9)^{\star}$ & $65(46.4)$ & $14(10.0)$ \\
\hline Lesion type $2(n=152)$ & $9.2(6.9-12.0)$ & $22.2(13.0-39.6)^{*}$ & $77(50.6)$ & $20(13.8)$ \\
\hline Lesion type 3, $4(n=12)$ & $11.0(6.8-12.9)$ & $21.2(16.1-58.1)^{\star}$ & $8(66.7)$ & $3(15.8)$ \\
\hline Single vessel $(n=267)$ & $9.3(7.0-11.8)$ & $16.4(10.9-28.9)^{*}$ & $140(52.4)$ & $19(8.1)$ \\
\hline Multiple vessels $(n=37)$ & $9.9(6.9-12.6)$ & $24.6(16.1-38.8)^{* 4}$ & $25(67.6)$ & $3(10.0)$ \\
\hline No-overlapping $(n=262)$ & $9.2(6.9-12.6)$ & $16.5(10.8-28.7)$ & $124(47.3)$ & $20(8.1)$ \\
\hline Overlapping $(n=42)$ & $11.4(7.7-13.0)$ & $41.1(24.8-64.9)^{\star \star 1}$ & $26(78.8)$ & $17(40.4)$ \\
\hline Predilatation $(n=184)$ & $9.0(6.8-12.2)$ & $20.6(11.8-40.5)^{\star}$ & $98(53.3)$ & $30(16.3)$ \\
\hline No predilation $(n=120)$ & $10.0(7.5-12.3)$ & $18.4(12.3-30.0)^{\star}$ & $52(43.3)$ & $7(5.8)$ \\
\hline Postdilatation $(n=97)$ & $10.0(7.5-12.3)$ & $18.4(12.3-30.0)^{*}$ & $62(63.9)$ & $21(21.6)$ \\
\hline No postdilation $(n=207)$ & $8.9(6.9-12.3)$ & $17.2(10.7-31.8)^{\star}$ & $96(46.4)$ & $16(7.7)$ \\
\hline Pre + post dilation $(n=76)$ & $9.8(7.0-12.0)$ & $25.0(13.3-57.2)^{* \bullet}$ & $41(77.6)$ & $16(21.0)$ \\
\hline No dilation $(n=95)$ & $9.7(7.4-12.3)$ & $15.5(11.0-29.9)$ & $52(54.7)$ & $6(6.3)$ \\
\hline $\operatorname{DES}(n=178)$ & $9.1(6.9-11.7)$ & $19.9(11.5-38.8)^{*}$ & $93(53.1)$ & $20(11.4)$ \\
\hline $\operatorname{BMS}(n=126)$ & $10.7(7.5-13.0)$ & $19.0(12.1-38.7)^{*}$ & $57(44.2)$ & 17 (13.2) \\
\hline
\end{tabular}

Pre-PCI hsTnT - preprocedural serum high-sensitivity troponin T level, post-PCI hsTnT-postprocedural serum high-sensitivity troponin T level, PMI - periprocedural myocardial injury, DES - drug-eluting stent, BMS - bare metal stent. Data are median (interquartile range) or number of patients (percentage). *Significantly higher than the respective pre-PCI hsTnT values. "Significantly higher than the respective values. Significantly higher than non-predilation group (mean \pm SD).

pairment and diabetes mellitus. As patients exhibiting heart failure or renal impairment had already been excluded in our study, continuous microscopic loss of cardiomyocytes during normal life or from cardiomyocyte renewal accelerated by aging may be the cause of this baseline elevation of cardiac troponins. Pre-procedural increased hsTnT levels of elderly patients can also be attributed to clustering of risk factors with advanced age, which may result in clinically silent ischemic episodes and small vessel occlusions, cardiomyocyte apoptosis and increased myocardial strain due to pressure or volume overload [18, 19].

Coronary lesion related factors such as plaque burden, multiple lesions, calcification, lesion eccentricity, bifurcation lesions and saphenous grafts may lead to PMI. We observed a higher incidence of PMI in multivessel $\mathrm{PCl}$ patients in the present study consistent with previous reports [15, 20, 21]. In addition, we have also demonstrated that overlapping stenting is associated with PMI. Similarly, longer stent length which indicates diffuse long segment atherosclerosis was also found to be associated with $\mathrm{PMI}$ in our study. A recent study investigating the impact of Syntax score for predicting PMI in patients undergoing elective $\mathrm{PCI}$ revealed that higher Syntax scores are predictive of myocardial injury [22]. These findings indicate that increased plaque burden either in a long single diffuse stenosis or in multiple lesions may lead to silent microvascular obstructions due to microembolization of plaque contents during $\mathrm{PCl}$.

Procedure-related variables such as aggressive stent expansion, side branch occlusion, side branch stenting, coronary dissection, vasospasm and distal embolization are all associated with PMI [15]. This observational study excluded patients with periprocedural evidence of intraluminal thrombus, coronary vasospasm, coronary dissection, and visible distal embolization which induced $\mathrm{PMI}$ following $\mathrm{PCl}$. We demonstrated that predilatation of lesions is associated with PMI and its extent during $\mathrm{PCl}$. There are still no studies indicating that predilatation may lead to PMI. However, the necessity of predilatation is often an indicator of lesion complexity, especially in cases of high-grade stenosis, severe calcification or chronic total occlusions which could result in procedure-related myonecrosis.

We also found that postdilatation with non-compliant balloons was associated with severe PMI. Postdilatation of stent struts may result in plaque extrusion and subsequent distal microembolization leading to myocardial necrosis. Overexpansion of a stent not only disrupts the atherosclerotic plaque but also causes local vessel injury which induces neuro-hormonal activation, oxidative stress, inflammation, platelet activation and micro- 
Table V. Impact of demographic, clinical and procedural factors on serum pre-procedural hsTnT, post-procedural hsTnT and the amount of increase in serum hsTnT concentrations following PCl

\begin{tabular}{|c|c|c|c|c|c|c|}
\hline \multirow[t]{2}{*}{ Influencing factors } & \multicolumn{2}{|c|}{ Pre-PCI hsTnT } & \multicolumn{2}{|c|}{ Post-PCI hsTnT } & \multicolumn{2}{|c|}{ Increase in hsTnT } \\
\hline & $\beta$ & $p$ & $\beta$ & $p$ & $\beta$ & $p$ \\
\hline \multicolumn{7}{|l|}{ Clinical factors: } \\
\hline $\mathrm{Age}^{*}$ & 0.077 & 0.002 & 0.087 & 0.157 & 0.100 & 0.112 \\
\hline Gender & 0.262 & 0.550 & 0.073 & 0.244 & 0.072 & 0.246 \\
\hline Smoking & -0.094 & 0.838 & 0.058 & 0.345 & 0.064 & 0.293 \\
\hline $\mathrm{DM}$ & 0.089 & 0.836 & -0.088 & 0.304 & -0.089 & 0.153 \\
\hline Hypertension & -0.254 & 0.628 & -0.078 & 0.304 & -0.071 & 0.338 \\
\hline Prior MI & -1.134 & 0.042 & -0.003 & 0.970 & 0.006 & 0.924 \\
\hline Prior PCl & 1.857 & 0.001 & 0.080 & 0.244 & 0.057 & 0.387 \\
\hline Prior CABG & 1.531 & 0.023 & 0.067 & 0.273 & 0.062 & 0.308 \\
\hline Statin use & -0.565 & 0.180 & -0.044 & 0.507 & -0.035 & 0.592 \\
\hline ACEI/ARB use & 1.707 & 0.001 & 0.059 & 0.438 & 0.017 & 0.815 \\
\hline$\beta$-Blocker use & -0.444 & 0.329 & 0.078 & 0.242 & 0.070 & 0.281 \\
\hline \multicolumn{7}{|l|}{ Procedural factors: } \\
\hline Predilation & & & 0.127 & 0.011 & 0.090 & 0.148 \\
\hline Postdilation & & & 0.080 & 0.180 & 0.069 & 0.250 \\
\hline Multivessel stenting & & & 0.042 & 0.492 & 0.048 & 0.441 \\
\hline Overlapping stenting & & & 0.102 & 0.003 & 0.063 & 0.370 \\
\hline Stent length ${ }^{\star *}$ & & & 0.222 & 0.001 & 0.172 & 0.027 \\
\hline
\end{tabular}

Pre-PCl hsTnT-preprocedural serum high-sensitivity troponin T level, post-PCl hsTnT-postprocedural serum high-sensitivity troponin T level, DM - diabetes mellitus, $M I$ - myocardial infarction, $P C I$ - percutaneous coronary intervention, CABG - coronary artery bypass grafting, ACEI/ARB - angiotensin-converting enzyme inhibitors/angiotensin receptor blockers. ${ }^{*}$ The unit for age is per 1 year increase. ${ }^{* *}$ The unit for stent length is per $1 \mathrm{~mm}$ increase. $\beta$ - $\beta$ coefficient, $p-$ probability value. $P<0.05$ indicates statistical significance. Data were derived from multivariate regression analysis.

vascular plugging of platelets and neutrophils. As a result of these activations, PMI may occur [15]. Total time of inflation and inflation maximal pressure were also found to be predictors of post-procedural elevation of cardiac troponins in another study by the same mechanisms [23]. Although post-dilatation is of great importance for optimal expansion of the stents, aggressive or unnecessary postdilatation should be avoided in the light of our findings. In addition, comparison of direct stenting and combination of predilatation and postdilatation also indicated a lower incidence of PMI in the direct stenting group in the present study, which strongly favors direct stenting in suitable cases.

High-sensitivite assays of cardiac troponins have been used in clinical practice with their property of superiority over conventional assays. Elevations of hsTnT above the $99^{\text {th }}$ percentile of URL can be detected in up to $2 \%$ of the general population who have stable CAD, renal failure, left ventricular hypertrophy or a combination of these co-morbidities [24]. Regardless of the cause, elevations of hsTnT are associated with adverse clinical outcomes in clinical conditions such as stable CAD, chronic heart failure, acute pulmonary embolism and pulmonary arterial hypertension. In addition to their ability to improve early diagnosis, hsTnT measurements allow more precise risk estimation for the above-mentioned clinical conditions compared with conventional assays [25]. Therefore, use of hsTnT in the diagnosis of PMI following uneventful PCI procedures provides more accurate evidence regarding myocardial necrosis and subsequent mortality risk of the patient compared with conventional assays.

Other cardiac biomarkers such as creatine kinase myocardial band (CK-MB) and inflammatory markers such as high-sensitivite C-reactive protein (hsCRP), which may provide additional information about the extent of myocardial necrosis and inflammation, were not measured. Myocardial injury detected by hsTnT was not evaluated with another modality such as cardiac magnetic resonance imaging, especially in cases of minor elevations, as to whether it deteriorated myocardial functions. In addition, a prospective clinical follow-up evaluating major cardiovascular events regarding post-procedural hsTnT subgroups was not performed.

\section{Conclusions}

High-sensitivite troponin measurements indicated a high incidence of periprocedural myocardial necrosis even though no clinical or procedural signs suggestive of 
myocardial injury existed during elective $\mathrm{PCI}$ procedures. The incidence of mild-moderate PMI and severe PMI was $49.3 \%$ and $12.2 \%$, respectively. Multivessel $\mathrm{PCl}$, overlapping stenting, predilatation, postdilatation and longer stent length were associated with procedure-related myocardial injury following elective $\mathrm{PCl}$.

\section{Conflict of interest}

The authors declare no conflict of interest.

\section{References}

1. Ioannidis JP, Karvouni E, Katritsis DG. Mortality risk conferred by small elevations of creatine kinase-MB isoenzyme after percutaneous coronary intervention. J Am Coll Cardiol 2003; 42: 1406-11.

2. Califf RM, Abdelmeguid AE, Kuntz RE, et al. Myonecrosis after revascularization procedures. J Am Coll Cardiol 1998; 31: 241-51.

3. Erbel R. Spontaneous and interventional coronary microembolisation. Heart 2003; 89: 986-9.

4. Thygesen K, Alpert JS, White HD; Joint ESC/ACCF/AHA/WHF Task Force for the Redefinition of Myocardial Infarction. Universal definition of myocardial infarction. Eur Heart J 2007; 28: 2525-38.

5. Thygesen K, Alpert JS, Jaffe AS, et al. Third universal definition of myocardial infarction. Eur Heart J 2012; 33: 2551-67.

6. Cuculi F, Lim CC, Banning AP. Periprocedural myocardial injury during elective percutaneous coronary intervention: is it important and how can it be prevented? Heart 2010; 96: 736-40.

7. Nageh T, Sherwood RA, Harris BM, et al. Prognostic role of cardiac troponin I after percutaneous coronary intervention in stable coronary disease. Heart 2005; 91: 1181-5.

8. Kizer JR, Muttrej MR, Matthai WH, et al. Role of cardiac troponin $T$ in the long-term risk stratification of patients undergoing percutaneous coronary intervention. Eur Heart J 2003; 24: 1314-22.

9. Reichlin T, Hochholzer W, Bassetti S, et al. Early diagnosis of myocardial infarction with sensitive cardiac troponin assays. N Engl J Med 2009; 361: 858-67.

10. Latini R, Masson S, Anand IS, et al. Prognostic value of very low plasma concentrations of troponin $T$ in patients with stable chronic heart failure. Circulation 2007; 116: 1242-9.

11. Omland T, de Lemos JA, Sabatine MS, et al. A sensitive cardiac troponin T assay in stable coronary artery disease. N Engl J Med 2009; 361: 2538-47.

12. Krone RJ, Shaw RE, Klein LW, et al. Evaluation of the American College of Cardiology/American Heart Association and the Society for Coronary Angiography and Interventions lesion classification system in the current stent era of coronary interventions (from the ACC-National Cardiovascular Data Registry). Am J Cardiol 2003; 92: 389-94.

13. Ryan TJ, Faxon DP, Gunnar RM, et al. Guidelines for percutaneous transluminal coronary angioplasty: a report of the American College of Cardiology/American Heart Association Task Force on assessment of diagnostic and therapeutic cardiovascular procedures (subcommittee on percutaneous transluminal coronary angioplasty). J Am Coll Cardiol 1988; 12: 529-45.

14. Alcock RF, Roy P, Adorini K, et al. Incidence and determinants of myocardial infarction following percutaneous coronary interventions according to the revised Joint Task Force definition of troponin T elevation. Int J Cardiol 2010; 140: 66-72.
15. Babu GG, Walker JM, Yellon DM, et al. Peri-procedural myocardial injury during percutaneous coronary intervention: an important target for cardioprotection. Eur Heart J 2011; 32: 23-31.

16. Chenevier-Gobeaux C, Meune C, Freund Y, et al. Influence of age and renal function on high-sensitivity cardiac troponin $T$ diagnostic accuracy for the diagnosis of acute myocardial infarction. Am J Cardiol 2013; 111: 1701-7.

17. Normann J, Mueller M, Biener M, et al. Effect of older age on diagnostic and prognostic performance of high-sensitivity troponin $\mathrm{T}$ in patients presenting to an emergency department. Am Heart J 2012; 164: 698-705.

18. Olivetti G, Abbi R, Quaini F, et al. Apoptosis in the failing human heart. N Engl J Med 1997; 336: 1131-41.

19. Wallace TW, Abdullah SM, Drazner MH, et al. Prevalence and determinants of troponin $\mathrm{T}$ elevation in the general population. Circulation 2006; 113: 1958-65.

20. Herrmann J. Peri-procedural myocardial injury: 2005 update. Eur Heart J 2005; 26: 2493-519.

21. Lansky AJ, Stone GW. Periprocedural myocardial infarction: prevalence, prognosis, and prevention. Circ Cardiovasc Interv 2010; 3: 602-10.

22. Van Gaal WJ, Ponnuthurai FA, Selvanayagam J, et al. The Syntax score predicts peri-procedural myocardial necrosis during percutaneous coronary intervention. Int J Cardiol 2009; 135: 60-5.

23. Saadeddin SM, Habbab MA, Sobki SH, et al. Minor myocardial injury after elective uncomplicated successful PTCA with or without stenting: detection by cardiac troponins. Catheter Cardiovasc Interv 2001; 53: 188-92.

24. Saunders JT, Nambi V, de Lemos JA, et al. Cardiac troponin T measured by a highly sensitive assay predicts coronary heart disease, heart failure, and mortality in the Atherosclerosis Risk in Communities Study. Circulation 2011; 123: 1367-76.

25. Thygesen K, Mair J, Giannitsis E, et al. How to use high-sensitivity cardiac troponins in acute cardiac care. Eur Heart J 2012; 33: 2252-7 